\section{Success of smell}

\section{F. H. Bronson}

The Scented Ape: The Blology and Culture of Human Odour. By Michael Stoddart. Cambridge University Press: 1990. Pp. 286. Hbk £40, \$80; pbk $£ 14.95, \$ 24.95$.

MosT mammals routinely broadcast selfidentifying chemical signals while going about their daily activities. This can be done passively while urinating, defecating or expelling breath; alternatively, it may involve the deliberate marking of objects in the mammal's environment with secretions of specialized skin glands. Among other things, the signals thereby transmitted function to advertise the approach of ovulation and hence a female's willingness to mate. The perception of these signals is by way of the primary or accessory olfactory systems. A central thesis of Michael Stoddart's The Scented Ape is that our pre-hominid ancestors probably routinely communicated their sexual readiness in this way, but that this became selectively disadvantageous when we began to hunt in groups and otherwise live gregariously. As a result, modern humans show only interesting vestiges of such chemical communication and, indeed, we are relatively anosmic compared to other mammals.

Stoddart is a zoologist and he formulates his arguments mostly within the framework of this discipline's comparative approach. Woven into these arguments, however, is an impressive blend of information from fields as diverse as psychoanalysis, steroid chemistry and archaeology. Side by side here are facts established unequivocally by experimentation with animals, isolated clinical observations and anecdotal impressions gained by historians. In his first chapter, Stoddart defends this need to blend the scientific with the less than scientific if we are to develop a truly meaningful understanding of the evolution of human odours and olfaction. Also included in this chapter is an entertaining discussion of the mediaeval belief that diseases were caused by bad odours.

Stoddart's second chapter focuses on the evolution of chemical communication and its relation to reproduction in the animal kingdom. The third chapter bears the same title as the book, and it considers human body odours, their chemistry and their potential use as signals. Among

\section{New in paperback}

- Beyond Mendel's Garden: Biotechnology in the Service of World Agriculture by Gabrielle J. Persley focuses on socioeconomic issues related to Third World development. Published by CAB International; price $£ 11.95, \$ 21$. other things, we are told here that despite being relatively hairless humans have denser aggregations of potentially odourproducing sebaceous glands than almost any other mammal. The fourth chapter focuses on the fact that the chemical signals of some mammals can passively control the secretion of reproductive hormones in recipient females and thus their ovulatory cycles. The unconvincing evidence that some such effects might occur even in humans is also considered here. The next chapter discusses the potential relationship between odours and mood, and the sixth and seventh chapters consider the history and biological implications of our use of perfumes and incense. Stoddart argues that in some cases these materials have been used to mask sexual signals and in other cases to mimic or enhance them.

The last two chapters of this book present the detailed arguments that underlie its central thesis. In brief, Stoddart argues that the prolonged postnatal dependency of infant humans promotes pair bonding in adults and hence either life-long or serial monogamy, and that these characteristics are of ancient origin. Banding together into larger groups for hunting and food sharing would threaten monogamy if females routinely advertised their sexual receptivity chemically. As a result, our lineage underwent olfactory desensitization, and now only vestiges of our former ability

\section{Molecular strings}

\section{W.W. Graessley}

Introduction to Polymer Dynamics. By Pierre Gilles de Gennes. Cambridge University Press: 1990. Pp. 57. HbK £20, $\$ 34.50$; pbk £6.95, \$12.95.

POLYMERS consisting of long, locally flexible chain molecules are commonplace in nature and in the everyday materials of commerce. Many of their properties, particularly in the liquid state, follow directly from such macromolecular features alone: the laws that relate structure and properties are insensitive to the precise chemical identity of the chain units themselves. This elementary picture of molecular strings, subject only to classical local interactions, has provided a theoretical basis for these laws since the very beginnings of polymer science. Advances have been especially rapid in the past 20 years, and the contributions of P.G. de Gennes to these advances have been profound.

The range of phenomena encompassed by the field is made clearly evident in this bricf volume, based on a series of lectures presented by Professor de Gennes to a to communicate chemically remain. Stoddart views this desensitization as an important preadaptation for many of the later changes that yielded our present mode of social organization.

These are interesting arguments. Some people will be convinced by them. Others will not. It is not necessary to be convinced by Stoddart's arguments to enjoy and profit from reading his book, however. It is most assuredly a scholarly effort, and the diversity of kinds of information it incorporates makes it exceptionally interesting to read. Upon thumbing through the pages of The Scented Ape, for example, one's eye might fall first on the sketch of a human mask shaped like a bird's head that was used in the Middle Ages to ward off the plague. Next one might see a table listing the primate species known to use manual exploration as well as sniffing and tasting to detect ovulation, then one might see tomb drawings illustrating the use of perfume, and, finally, the photograph of a frankincense tree and a map showing the present day range of this species.

Stoddart has written an important book that will stimulate considerable argument. Reading it will prove both enjoyable and profitable not only for students of olfaction, but for anyone interested even in passing in human evolution or reproduction.

F. H. Bronson is in the Institute of Reproductive Biology. Department of Zoology, University of Texas, Austin, Texas 78712, USA.

broad audience at the Politecnico di Milano in 1986. The main ideas about dynamics in both isolated and concentrated chain liquids are outlined in the opening chapter. The second chapter is devoted to a rather specific biological question, the minimum size of flexible chain spacers for the receptor site units in globular proteins. The third deals with the spreading of liquids on solids, with only some incidental remarks on the special situation of polymeric liquids. The last chapter discusses in some detail the remarkable influence of dilute polymer chains on turbulent flows. The overall aim is to convey essential concepts with a minimum of mathematical formalism. This is accomplished reasonably well, although, perhaps owing to a diverse subject matter, the level of presentation is somewhat uneven. Important and nonobvious results are merely quoted in some cases, yet worked out with care and completeness in others. Nevertheless, the book does succeed in offering the newcomer a tantalizing glimpse of polymer theory through some selected topics and a few well chosen references to the literature.

W.W. Graessley is in the Department of Chemical Engineering, Princeton University, Princeton. New Jersey 08544, USA. 